\title{
Energy Scarcity: A Theoretical Analysis of Substitution and Technical Change $^{+}$
}

\author{
Shelby Gerking \\ and \\ William Schulze*
}

\section{INTRODUCTION}

Just how well the United States can adjust to increasingly scarce fuels may, in a large part, determine the future health of the U.S. economy. However, questions relating to the "essentiality" of energy have taken the form of a debate between advocates of opposing positions. The first view is that energy from depletable natural resources is necessary for the survival of mankind and so "we," the present generation, have an ethical obligation to conserve such resources to the maximum extent possible. Georgescu-Roegen (1975) has elegantly presented this viewpoint in a number of forms, concluding that drastic current action is appropriate. Alternatively, Solow (1974), Stiglitz (1974) and others have taken a polar opposite position based on studies of aggregate growth models constrained by depletable resources. They conclude: (i) that if substitution possibilities are "good enough," no problem exists for mankind's long run prospects and (ii) that even if natural resources are limiting, as long as extraction occurs in a competitive economy, we will undergo an "optimal" resource depletion, even if that depletion terminates mankind's economic development. Thus, the only actions necessary now are to improve the efficiency of markets, particularly intertemporal markets for natural resources.

This paper represents an attempt to explore the intermediate ground between the two polar positions described above. In particular, we examine energy substitutability and technical change in a simple general equilibrium model which incorporates an energy related intermediate good (e.g., electricity) as well as capital, labor, and a single natural resource or energy input (e.g., oil or coal). Final demand consists of a portion of the intermediate energy commodity (electricity) and a composite commodity (manufactured

\footnotetext{
tWe are grateful for the helpful comments by V. Kerry Smith, Raymond Kopp, Miles Sonstegaard and an anonymous reviewer. All remaining errors and conclusions are the sole responsibility of the authors. An earlier version of this paper was presented at the RFF-EPRI workshop on The Modeling of Natural Resource Price Movements, June 28-29, 1979.
}

* Department of Economics, University of Wyoming, Laramie, Wyoming 82071 
goods). Even this simplistic framework produces ambiguous and complex results in analyzing an exogenous change in the scarcity value of an energy resource which must be paid as economic rent to resource owners. Our general equilibrium analysis leads us (i) to conclude that use of an aggregate production function is likely to be misleading and (ii) to suggest a number of critical parameters for analysis in untangling the response of a competitive economy to changing resource scarcity.

Although intuitively obvious, the properties of aggregate production functions, in particular the Cobb-Douglas function as used by Stiglitz (1974) and others, are shown in Figure 1. $\mathrm{I}_{0}$ and $\mathrm{I}_{1}$ are isoquants for the production of aggregate output from, in this case, capital $(\mathrm{K})$ and use of a depletable natural resource $(N)$. We begin at point $A$ using $N_{A}$ and $\bar{K}$ with the price ratio for these factors (in a competitive economy) tangent to $\mathrm{I}_{0}$ at $\mathrm{A}$. If the price of $\mathrm{N}$ rises with respect to $\mathrm{K}$, reflecting energy scarcity, the output level can be maintained by simply moving along $\mathrm{I}_{0}$ to $\mathrm{B}$ reducing $\mathrm{N}$ to $\mathrm{N}_{\mathrm{B}}$ and increasing $\mathrm{K}$ to $\mathrm{K}_{\mathrm{B}}$. In fact, as Stiglitz has shown, depending on the elasticity of substitution between $\mathrm{N}$ and $\mathrm{K}$, it may be possible to continue to move along $\mathrm{I}_{0}$ over time "forever" substituting $\mathrm{K}$ for $\mathrm{N}$ holding output and consumption constant where in the limit $\mathrm{K} \rightarrow \infty$ and $\mathrm{N} \rightarrow 0$ and total resource use, $\int_{0}^{\infty} \mathrm{N}$ (T) $\mathrm{dT}$, is finite (where $\mathrm{T}$ denotes time). Clearly this is only possible because Cobb-Douglas isoquants such as $I_{0}$ are asymptotic to the axes. We find asymptotic properties of limited interest for the current energy dilemma. For further discussion of these issues see Cummings and Schulze (1980).

More important with respect to our own comparative static analysis are the shorter run consequences of substitution and technical change. Technical change is represented in the figure by an inward shift of $I_{0}$ to $I_{1}$ where both isoquants represent the same level of output. If, in the short run, the price of the energy resource again rises relative to capital but capital remains constant at $\overline{\mathrm{K}}$ and technical change occurs shifting $\mathrm{I}_{0}$ to $\mathrm{I}_{1}$, we will now move from $\mathrm{A}$ to $\mathrm{C}$ in Figure 1. The use of the natural resource will drop from $\mathrm{N}_{\mathrm{A}}$ to $\mathrm{N}_{C}$. This movement can be broken into two parts. $\mathrm{N}_{A}$ to $\mathrm{N}_{B}$ results from the substitution effect associated with an increase in energy price while $N_{B}$ to $N_{C}$ results from the neutral technical change associated with Cobb-Douglas production functions. Note then that in a comparative static framework, the use of such an aggregate production function implies that (i) an increase in energy resource price always reduces energy use and (ii) technical change always reduces energy use as well. In developing a simple general equilibrium model with an intermediate energy commodity we challenge both of these assumptions implicit in aggregate growth models.

The plan of this paper is then to develop a general equilibrium model of the effects of changing resource scarcity values in Section II, to examine the impact of such changes in Section III, and to comment on possible empirical measures of energy substitution possibilities (conservation) and technical change as they affect energy policy in light of the analyses in Section IV. We should point out that, in many respects, this research is an attempt to extend an 


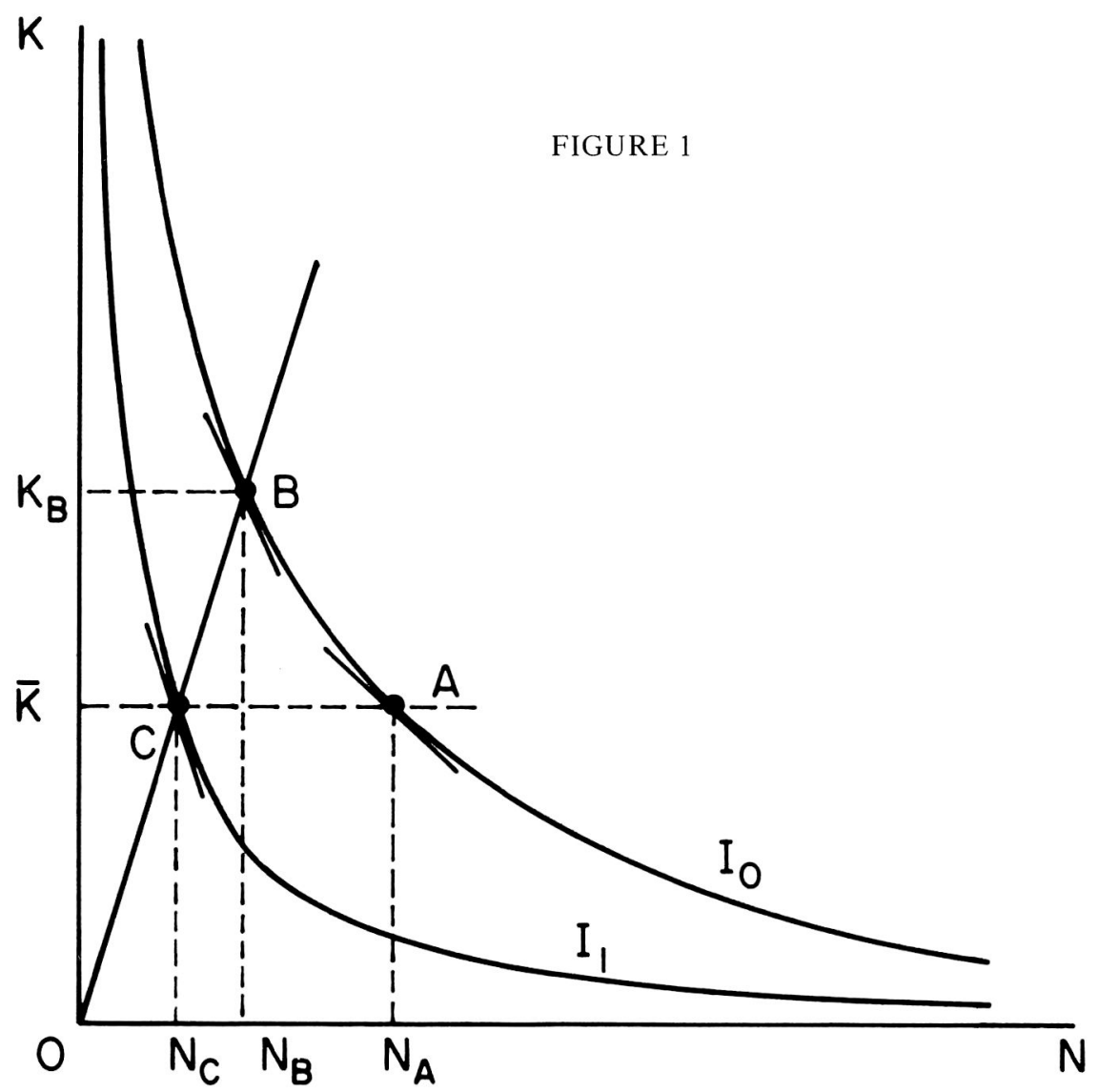

approach taken by Smith (1978) where, however, the objective here is to apply the analysis specifically to the current energy situation. This allows us to impose considerably more structure on the economic analysis, but does limit the generality of the results.

\section{THE MODEL}

In the model developed here, three classes of commodities are produced: (1) manufactured products and services (X), (2) electricity (E), and (3) a natural resource energy commodity $(N)$. All of the output of $X$ is assumed to be purchased by households, while $\mathrm{E}$ may be purchased either by households or by producers of $\mathrm{X}$. The amount of electricity used by households is subsequently referred to as residential sales and denoted $E_{R}$ and the amount of electricity used in the production of $X$, denoted $E_{X}$, is identified with commercial sales; $E_{R}+E_{X}=E$. $N$ is a pure intermediate input to the production of both $\mathrm{X}$ and $\mathrm{E}$ and can be thought of as coal or fuels such as oil and natural gas. Therefore, in the production of $\mathrm{X}$, firms are free to substitute between the use of $\mathrm{N}$ and $\mathrm{E}$ within the technological limits defined by their production 
functions. On the other hand, since the model contains only one resource commodity, questions relating to inter-fuel substitution in the production of electricity are ignored. This particular simplification is justifiable in the present context for two reasons. First, the primary focus in the discussion to follow is on the price and production levels of $\mathrm{X}$ and $\mathrm{E}$ given an exogenous change in natural resource prices, rather than on any change in the relative prices or rates of production for different natural resources. Second, the production of more natural resources may be added to the model without changing the basic structure of the results. ${ }^{1}$

Manufactured goods and services (X) are produced according to the production function

$$
X=F_{X}\left(E_{X}, N_{X}, K_{X}, L_{X}\right)
$$

where two factors, electricity and natural resources used in the production of $X\left(E_{X}\right.$ and $\left.N_{X}\right)$ have already been discussed while the remaining two are the unproduced primary inputs; capital $\left(\mathrm{K}_{\mathrm{X}}\right)$ and labor $\left(\mathrm{L}_{\mathrm{X}}\right)$. Production of electricity occurs according to

$$
E=F_{E}\left(N_{E}, K_{E}\right)
$$

where the utilization of labor in the production of $\mathrm{E}$ is assumed to be sufficiently small that it can be ignored. Finally, $\mathrm{N}$ is processed using capital and labor

$$
\mathrm{N}=\mathrm{F}_{\mathrm{N}}\left(\mathrm{L}_{\mathrm{N}}, \mathrm{K}_{\mathrm{N}}\right)
$$

Any electricity required to produce $\mathrm{N}$ is assumed to be generated internally within the natural resource sector. Hence, $\mathrm{N}$ is a net energy concept. ${ }^{2}$

The production relations that describe the model are quite similar to those employed by Batra (1973) and are based upon two assumptions: (1) constant returns to scale exists in the production of all three classes of commodities and (2) all markets exhibit competitive equilibrium. Taken together, these assumptions imply that all productive factors are fully employed and that entrepreneurs earn zero economic profits. Although these assumptions of long run competitive equilibrium are restrictive, they are employed in this first examination of the problem of hand because they enable us to streamline the analysis and permit greater focus on the key trade offs that occur when the natural resource scarcity value changes. Algebraically, the full employment conditions are

$$
\begin{aligned}
& C_{L X} X+C_{L N} N=L \\
& C_{K K} X+C_{K E} E+C_{K N} N=K \\
& C_{N X} X+C_{N E} E=N
\end{aligned}
$$


where $C_{i j}$ in Equations (4), (5), and (6) are input-output coefficients interpreted as the average amount of factor $\mathrm{i}(\mathrm{i}=\mathrm{L}, \mathrm{K}, \mathrm{N})$ used to produce one unit of commodity $j(j=X, E, N)$. However, there is one remaining input-output coefficient that must be defined. This is $C_{E X}$, the average amount of electricity used per unit of output of $X$. Since $C_{E X}=E_{X} / X$ and since $E=E_{R}$ $+E_{X}$, Equations (5) and (6) may be rewritten in order to explicitly incorporate this production parameter as

$$
\begin{aligned}
& \left(C_{K X}+C_{E X} C_{K E}\right) X+C_{K E} E_{R}+C_{K N} N=K \\
& \left(C_{N X}+C_{E X} C_{N E}\right) X+C_{N E} E_{R}=N
\end{aligned}
$$

The zero profit equations are

$$
\begin{aligned}
& C_{L X} \mathrm{w}+\mathrm{C}_{K X} \mathrm{r}+\mathrm{C}_{E X} \mathrm{P}_{E}+\mathrm{C}_{N X} \mathrm{P}_{\mathrm{N}}=\mathrm{P}_{X} \\
& \mathrm{C}_{\mathrm{KE}} \mathrm{r}+\mathrm{C}_{\mathrm{NE}} \mathrm{P}_{N}=\mathrm{P}_{E} \\
& \mathrm{C}_{\mathrm{LN}} \mathrm{w}+\mathrm{C}_{\mathrm{KN}} \mathrm{r}=\overline{\mathrm{P}}_{\mathrm{N}}=(1-\delta) \mathrm{P}_{\mathrm{N}} ; 0 \leq \delta \leq 1
\end{aligned}
$$

where $w$ denotes the wage rate paid to labor, $r$ denotes the rental rate of return on capital, $\mathrm{P}_{\mathrm{E}}$ denotes the price per unit of electricity, ${ }^{3} \mathrm{P}_{\mathrm{X}}$ denotes the price per unit of $X, P_{N}$ denotes the price per unit of $N$, and $\bar{P}_{N}$ denotes the processing costs per unit of $\mathrm{N}$. As shown in Equation $(9), \overline{\mathrm{P}}_{\mathrm{N}}=(1-\delta) \mathrm{P}_{\mathrm{N}}$ which indicates that only a part of $\mathrm{P}_{\mathrm{N}}$ is actually distributed to labor and capital. The remainder, $\mathrm{S}_{\mathrm{N}}=\mathrm{P}_{\mathrm{N}}-\overline{\mathrm{P}}_{\mathrm{N}}$, accrues as a scarcity value or rent payment to the owners of the natural resource. Using the definition of $\mathrm{S}_{\mathrm{N}}, \delta=\mathrm{S}_{\mathrm{N}} / \mathrm{P}_{\mathrm{N}}$ and is the fraction of $\mathrm{P}_{\mathrm{N}}$ that is returned to the original owners of $\mathrm{N}$. The depletable nature of the natural resource, $\mathrm{N}$, is reflected in the model by increases in the scarcity price of the resource, $\mathrm{S}_{\mathrm{N}}$. For example, if the stock of a uniform quality natural resource is known, then, in a competitive market, the scarcity value of the resource, $\mathrm{S}_{\mathrm{N}}$, paid to resource owners will rise at a percentage rate equal to the rate of interest as shown by Hotelling (1931).

In Equations (4), (5a), (6a), (7), (8), and (9), the variables treated as endogenous are $X, E_{R}, N, w, r$, and $\bar{P}_{N}$. Also, since $E_{X}=C_{E X} X$, both $E_{X}$ and $E$ are determined within the model. On the other hand, the endowments of the primary factors $\mathrm{K}$ and $\mathrm{L}$ are assumed to be fixed in supply. The scarcity value of the natural resource, $\mathrm{S}_{\mathrm{N}}$, is assumed to be determined by exogenous factors as well. Finally, the model is closed; that is, the relative price $\mathrm{P}_{E} / \mathrm{P}_{X}$ is determined; by adding the demand relation

$$
E_{R} / X=f\left(P_{E} / P_{X}\right)=f(P) ; P=P_{E} / P_{X} .
$$

This demand relation assumes that household tastes are identical and homothetic.

As previously indicated, the primary focus of this paper is on the response of the model's endogenous variables to exogenous shifts in natural resource scarcity values and to improvements in the technological relations governing 
the way natural resources are used. In order to determine these responses in the most algebraically tractable way, the full employment equations are collapsed by substituting (6a) into (5a) and (4) so as to eliminate $\mathrm{N}$ and are then re-expressed in relative rates of change. ${ }^{4}$ The resulting two equations are

$$
\begin{aligned}
& \lambda_{\mathrm{LX}} \mathrm{X}^{*}+\lambda_{\mathrm{LE}} \mathrm{E}_{\mathrm{R}}^{*}=\mathrm{L}^{*}-\lambda_{\mathrm{LX}} \mathrm{R}_{\mathrm{LX}}^{*}-\lambda_{\mathrm{LE}} \mathrm{R}_{\mathrm{LE}}^{*} \\
& \lambda_{\mathrm{KX}} \mathrm{X}^{*}+\lambda_{\mathrm{KE}} \mathrm{E}_{\mathrm{R}}^{*}=\mathrm{K}^{*}-\lambda_{\mathrm{KX}} \mathrm{R}_{\mathrm{KX}}^{*}-\lambda_{\mathrm{KE}} \mathrm{R}_{\mathrm{KE}}^{*}
\end{aligned}
$$

In equations (11) and (12), the $\mathrm{R}_{\mathrm{ij}}$ are defined according to

$$
\begin{aligned}
& \mathrm{R}_{\mathrm{LX}}=\mathrm{C}_{\mathrm{LX}}+\mathrm{C}_{\mathrm{LN}}\left(\mathrm{C}_{\mathrm{NX}}+\mathrm{C}_{\mathrm{EX}} \mathrm{C}_{\mathrm{NE}}\right) \\
& \mathrm{R}_{\mathrm{LE}}=\mathrm{C}_{\mathrm{LN}} \mathrm{C}_{\mathrm{NE}} \\
& \mathrm{R}_{\mathrm{KX}}=\mathrm{C}_{\mathrm{KX}}+\mathrm{C}_{\mathrm{EX}} \mathrm{C}_{\mathrm{KE}}+\mathrm{C}_{\mathrm{KN}}\left(\mathrm{C}_{\mathrm{NX}}+\mathrm{C}_{\mathrm{EX}} \mathrm{C}_{\mathrm{NE}}\right) \\
& \mathrm{R}_{\mathrm{KE}}=\mathrm{C}_{\mathrm{KN}} \mathrm{C}_{\mathrm{NE}}+\mathrm{C}_{\mathrm{KE}}
\end{aligned}
$$

and are interpreted as the total requirement of primary factor $i$ used per unit of final commodity $\mathrm{j}$. In addition, $\lambda_{\mathrm{LX}}=\mathrm{XR}_{\mathrm{LX}} / \mathrm{L}$ denotes the fraction of the labor endowment used both directly and indirectly in the production of $\mathrm{X}$ (the remaining $\lambda_{\mathrm{ij}}$ are analogously defined) and $\mathrm{Z}^{*}=\mathrm{dZ} / \mathrm{Z}$.

Similarly, the zero profit equations are first expressed in relative rates of change as

$$
\begin{aligned}
& \rho_{\mathrm{LX}} \mathrm{W}^{*}+\rho_{\mathrm{KX}} \mathrm{r}^{*}+\rho_{\mathrm{EX}} \mathrm{P}_{\mathrm{E}}^{*}+\rho_{\mathrm{NX}} \mathrm{P}_{\mathrm{N}}^{*}=\mathrm{P}_{\mathrm{X}}{ }^{*}-\mathrm{D}_{\mathrm{X}} \mathrm{t}^{*} \\
& \rho_{\mathrm{KE}} \mathrm{r}^{*}+\rho_{\mathrm{NE}} \mathrm{P}_{\mathrm{N}}^{*}=\mathrm{P}_{\mathrm{E}}^{*}-\mathrm{D}_{\mathrm{E}} \mathrm{t}^{*} \\
& \rho_{\mathrm{LN}} \mathrm{W}^{*}+\rho_{\mathrm{KN}} \mathrm{r}^{*}=\mathrm{P}_{\mathrm{N}}^{*}-\phi \delta^{*}-\mathrm{D}_{\mathrm{N}} \mathrm{t}^{*}
\end{aligned}
$$

In the three equations above, $\rho_{\mathrm{LX}}=\mathrm{wC}_{\mathrm{LX}} / \mathrm{P}_{\mathrm{X}}$ denotes the net distributive share paid to labor in the production of $\mathrm{X}$ and the remaining $\rho_{\mathrm{ij}}$ are analogously defined. Also, these equations are simplified through the imposition of cost minimization conditions. More specifically, since all production exhibits constant returns to scale, the $C_{i j}$ can be written as functions of the input prices and a factor augmenting technical progress parameter, $\mathrm{t}$

$$
C_{i j}=C_{i j}\left(w, r, P_{E}, P_{N}, t\right)
$$

Therefore, in relative rates of change,

$$
C_{i j}^{*}=A_{i j}^{*}+B_{i j}^{*}
$$

where

$$
A_{i j}^{*}=\frac{1}{C_{i j}}\left[\frac{\partial C_{i j}}{\partial W} d w+\frac{\partial C_{i j}}{\partial r} d r+\frac{\partial C_{i j}}{\partial P_{E}} d P_{E}+\frac{\partial C_{i j}}{\partial P_{N}} d P_{N}\right]
$$


and

$$
B_{i j}^{*}=\frac{1}{C_{i j}} \frac{\partial C_{i j}}{\partial t}
$$

at a given level of production, tangency between the isoquant surface and the isocost plane requires that

$$
\begin{aligned}
& \rho_{\mathrm{LX}} \mathrm{A}_{\mathrm{LX}}^{*}+\rho_{\mathrm{KX}} \mathrm{A}_{\mathrm{KX}}^{*}+\rho_{\mathrm{EX}} \mathrm{A}_{\mathrm{EX}}^{*}+\rho_{\mathrm{NX}} \mathrm{A}_{\mathrm{NX}}^{*}=0 \\
& \rho_{\mathrm{KE}} \mathrm{A}_{\mathrm{KE}}^{*}+\rho_{\mathrm{NE}} \mathrm{A}_{\mathrm{NE}}^{*}=0 \\
& \rho_{\mathrm{LN}} \mathrm{A}_{\mathrm{LN}}^{*}+\rho_{\mathrm{KN}} \mathrm{A}_{\mathrm{KN}}^{*}=0
\end{aligned}
$$

Hence, the $D_{j}$, which can be written as

$$
\mathrm{D}_{\mathrm{j}}=\Sigma_{\mathrm{i}} \rho_{\mathrm{ij}} \frac{\partial \mathrm{C}_{\mathrm{ij}}}{\partial \mathrm{t}} \frac{\mathrm{t}}{\mathrm{C}_{\mathrm{ij}}}
$$

is interpreted as the weighted average of the elasticity of the input-output coefficients for commodity $\mathrm{j}$ with respect to the technical progress parameter $\mathrm{t}$ where the weights (the $\rho_{\mathrm{ij}}$ ) measure the relative importance of each of the inputs. These three zero profit equations may now be collapsed by eliminating $\mathrm{P}_{\mathrm{E}}^{*}$ and $\mathrm{P}_{\mathrm{N}}^{*}$ from the left hand sides of (17) and (18). This manipulation results in

$$
\begin{aligned}
& \theta_{\mathrm{LX}} \mathrm{W}^{*}+\theta_{\mathrm{KX}} \mathrm{r}^{*}=\mathrm{P}_{\mathrm{X}}{ }^{*}-\phi_{\mathrm{X}} \delta^{*}-\pi_{\mathrm{X}} \mathrm{t}^{*} \\
& \theta_{\mathrm{LE}} \mathrm{W}^{*}+\theta_{\mathrm{KE}} \mathrm{r}^{*}=\mathrm{P}_{\mathrm{E}}^{*}-\phi_{\mathrm{E}} \delta^{*}-\pi_{\mathrm{E}} \mathrm{t}^{*}
\end{aligned}
$$

where

$$
\begin{aligned}
& \theta_{\mathrm{LX}}=\rho_{\mathrm{LX}}+\rho_{\mathrm{LN}}\left(\rho_{\mathrm{NX}}+\rho_{\mathrm{EX}} \rho_{\mathrm{NE}}\right) \\
& \theta_{\mathrm{LE}}=\rho_{\mathrm{LN}} \rho_{\mathrm{NE}} \\
& \theta_{\mathrm{KX}}=\rho_{\mathrm{KX}}+\rho_{\mathrm{EX}} \rho_{\mathrm{KE}}+\rho_{\mathrm{KN}}\left(\rho_{\mathrm{NX}}+\rho_{\mathrm{EX}} \rho_{\mathrm{NE}}\right) \\
& \theta_{\mathrm{KE}}=\rho_{\mathrm{KE}}+\rho_{\mathrm{NE}} \rho_{\mathrm{KN}} \\
& \phi_{\mathrm{X}}=\phi\left(\rho_{\mathrm{RC}} \rho_{\mathrm{NE}}+\rho_{\mathrm{NX}}\right) \\
& \phi_{\mathrm{E}}=\phi \rho_{\mathrm{NE}} \\
& \pi_{\mathrm{X}}=\mathrm{D}_{\mathrm{X}}+\rho_{\mathrm{EX}} \mathrm{D}_{\mathrm{E}}+\left(\rho_{\mathrm{NX}}+\rho_{\mathrm{EX}} \rho_{\mathrm{NE}}\right) \mathrm{D}_{\mathrm{N}} \\
& \pi_{\mathrm{E}}=\mathrm{D}_{\mathrm{E}}+\rho_{\mathrm{NE}} \mathrm{D}_{\mathrm{N}}
\end{aligned}
$$


In addition, the $\theta_{\mathrm{ij}}$ are interpreted as the total distributive share of primary factor $\mathrm{i}$ in the production of commodity $\mathrm{j}$, while $\phi_{\mathrm{j}}$ denotes the total percentage increase in costs to produce commodity $\mathrm{j}$ resulting from a one percent increase in $\delta$ and $\pi_{j}$ denotes the total percentage reduction in costs to produce commodity $\mathrm{j}$ associated with a one percent increase in t. Finally, the demand relation in Equation (1) may be written in relative rates of change as

$$
\mathrm{G}^{*}-\mathrm{X}^{*}=\alpha \mathrm{pP}^{*} ; \quad \alpha_{\rho} \leq 0
$$

where $\alpha \mathrm{p}$ denotes the elasticity of substitution by households in the consumpi. if $\mathrm{E}_{\mathrm{R}}$ and $\mathrm{X} .^{5}$

Lefore the model can be solved for the effects of changes in $\delta$ and in the $\mathrm{R}_{\mathrm{ij}}^{*}$ in Equations (11) and (12) must be rewritten in terms of $\mathrm{w}^{*}, \mathrm{r}^{*}, \delta^{*}$ and $\mathrm{t}^{*}$. This straight-forward, but rather tedious task results in expressions of the form

$$
\mathrm{R}_{\mathrm{ij}}^{*}=\gamma_{\mathrm{ij}}\left(\mathrm{w}^{*}-\mathrm{r}^{*}\right)+\mu_{\mathrm{ij}} \delta^{*}+\beta_{\mathrm{ij}} \mathrm{t}^{*} \quad \mathrm{i}=\mathrm{L}, \mathrm{K} \quad \mathrm{j}=\mathrm{X}, \mathrm{E}
$$

where the procedure for obtaining exact expressions for the $\gamma_{\mathrm{ij}}, \mu_{\mathrm{ij}}$, and $\beta_{\mathrm{ij}}$ is described in greater detail in Appendix A.

These deviations may be used in connection with Equations (11) and (12) to write

$$
\begin{aligned}
& \lambda_{\mathrm{LX}} \mathrm{X}^{*}+\lambda_{\mathrm{LE}} \mathrm{E}^{*}+\gamma_{\mathrm{L}}\left(\mathrm{w}^{*}-\mathrm{r}^{*}\right)=\mathrm{L}^{*}-\mu_{\mathrm{L}} \delta^{*}-\beta_{\mathrm{L}} \mathrm{t}^{*} \\
& \lambda_{\mathrm{KX}} \mathrm{X}^{*}+\lambda_{\mathrm{LE}} \mathrm{E}^{*}+\gamma_{\mathrm{K}}\left(\mathrm{w}^{*}-\mathrm{r}^{*}\right)=\mathrm{K}^{*}-\mu_{\mathrm{K}} \delta^{*}-\beta_{\mathrm{K}} \mathrm{t}^{*}
\end{aligned}
$$

where

$$
\begin{array}{ll}
\gamma_{\mathrm{i}}=\lambda_{\mathrm{iX}} \gamma_{\mathrm{iX}}+\lambda_{\mathrm{iE}} \gamma_{\mathrm{iE}} & \mathrm{i}=\mathrm{L}, \mathrm{K} \\
\beta_{\mathrm{i}}=\lambda_{\mathrm{iX}} \beta_{\mathrm{iX}}+\lambda_{\mathrm{iE}} \beta_{\mathrm{iE}} & \mathrm{i}=\mathrm{L}, \mathrm{K} \\
\mu_{\mathrm{i}}=\lambda_{\mathrm{iX}} \mu_{\mathrm{iX}}+\lambda_{\mathrm{iE}} \mu_{\mathrm{iE}} &
\end{array}
$$

In Equation (42), $\gamma_{\mathrm{L}}\left(\gamma_{\mathrm{K}}\right)$ is interpreted as the aggregate percentage direct and indirect savings on labor (capital) that would occur at unchanged output, technology, and resource scarcity values if the wage rate (rate of return on capital) increased (decreased) by one percent. ${ }^{6}$ As shown in Appendix A, $\gamma_{\mathrm{LX}}, \gamma_{\mathrm{LE}}$, and thus $\gamma_{\mathrm{L}}$ are less than zero while $\gamma_{\mathrm{KX}}, \gamma_{\mathrm{KE}}$, and $\gamma_{\mathrm{K}}$ are greater than zero provided that all factors are substitutes in the production of all goods. Next, the $\beta_{\mathrm{i}}(\mathrm{i}=\mathrm{L}, \mathrm{K})$ are defined analogously with the $\gamma_{\mathrm{i}}$. For example, $\beta_{\mathrm{L}}\left(\beta_{\mathrm{K}}\right)$ is interpreted as the aggregate percentage direct and indirect savings on $\mathrm{L}(\mathrm{K})$ that would occur at unchanged output levels, factor rewards, and resource scarcity values if $t$ increased by one percent. Both $\beta_{L}$ and $\beta_{K}$ are, therefore, negative in sign. Finally, the $\mu_{\mathrm{i}}(\mathrm{i}=\mathrm{L}, \mathrm{K})$ represent the aggregate percentage direct and indirect savings on factor $\mathrm{i}$ that would result at 
unchanged output levels, technology, and factor rewards, if $\delta$ increased by one percent. However, in contrast to the $\gamma_{\mathrm{i}}$, the $\mu_{\mathrm{i}}$ are not unambiguously signed. In the case of $\mu_{\mathrm{L}}$ the coefficients on $\sigma_{\mathrm{LE}}^{\mathrm{X}}$ and $\sigma_{\mathrm{LN}}^{\mathrm{X}}$ are positive while those on $\sigma_{\mathrm{KE}}^{\mathrm{X}}$ and $\sigma_{\mathrm{KN}}^{\mathrm{X}}$ are negative. ${ }^{7}$ Considering these four terms separately, this implies that an increase in the scarcity value of $\mathrm{N}$ will tend to increase the economy's demand for labor (through increasing $R_{L X}$ ) if there exists greater substitution possibilities between $L$ and $E_{X}$ and $L$ and $N$ than between $K$ and $E_{X}$ and $K$ and $N$ in the production of $X$. Also, the negative coefficient on $\sigma_{\mathrm{KN}}^{\mathrm{E}}$ indicates that as $\mathrm{S}_{\mathrm{N}}$ rises causing a substitution in favor of producing electricity by more capital intensive methods, then the electricity purchased by producers of $\mathrm{X}$ will embody more capital and less labor. This shift in the capital/labor embodiment of $E$ occurs because $\mathrm{L}$ is used in the production of $\mathrm{N}$ but not in the production of $\mathrm{E}$ and would tend to have a negative effect upon $\mathrm{R}_{\mathrm{LX}}$. Finally, the negative coefficient on $\sigma_{\mathrm{NE}}^{\mathrm{X}}$ means that if $\mathrm{S}_{\mathrm{N}}$ rises, there will be a substitution away from $N$ and into $E_{X}$ in the production of $X$. Again, because $\mathrm{N}$ but not $\mathrm{E}$ uses $\mathrm{L}$, this would tend to have a negative effect upon $\mathrm{R}_{\mathrm{LX}}$. Unfortunately, little more can be said regarding the sign of $\mu_{\mathrm{L}}$ except that it obviously depends upon the relative strengths of these competing effects. Nevertheless, a comparison of the expressions for $\mu_{\mathrm{L}}$ and $\mu_{\mathrm{K}}$ in Appendix A produces the useful conclusion that if: (1) $\mu_{\mathrm{L}}>0$ then $\left(\mu_{\mathrm{L}}-\mu_{\mathrm{K}}\right)<$ 0 and (2) all production functions are of the fixed proportions type $\left(\sigma_{\mathrm{ij}}^{\mathrm{k}}=0\right.$ for all $\mathbf{i}, \mathbf{j}$, and $\mathrm{k}$ ) then $\mu_{\mathrm{L}}=\mu_{\mathrm{K}}=0$.

At this point, the specification of the model is complete. In particular, it is desçribed by Equations (28), (29), (38), (40) and (41). In matrix form, these equations can be written as:

$$
\left[\begin{array}{ccccc}
\lambda_{\mathrm{LX}} & \lambda_{\mathrm{LE}} & \gamma_{\mathrm{L}} & -\gamma_{\mathrm{L}} & 0 \\
\lambda_{\mathrm{KX}} & \lambda_{\mathrm{KE}} & \gamma_{\mathrm{K}} & -\gamma_{\mathrm{K}} & 0 \\
0 & 0 & \theta_{\mathrm{LX}} & \theta_{\mathrm{KX}} & 0 \\
0 & 0 & \theta_{\mathrm{LE}} & \theta_{\mathrm{KE}} & -1 \\
1 & -1 & 0 & 0 & -\alpha_{\rho}
\end{array}\right]\left[\begin{array}{c}
\mathrm{X}^{*} \\
\mathrm{E}_{\mathrm{R}}^{*} \\
\mathrm{w}^{*} \\
\mathrm{r}^{*} \\
\mathrm{P}^{*}
\end{array}\right]=\left[\begin{array}{c}
\mathrm{L}^{*}-\mu_{\mathrm{L}} \delta^{*}-\beta_{\mathrm{L}^{*}} \\
\mathrm{~K}^{*}-\mu_{\mathrm{K}} \delta^{*}-\beta_{\mathrm{K}^{*}} \\
-\phi_{\mathrm{X}} \delta^{*}-\pi_{\mathrm{X}^{*}} \\
-\phi_{\mathrm{E}} \delta^{*}-\pi_{\mathrm{E}^{*}} \\
0
\end{array}\right]
$$

Attention is now directed to showing how changes in $\delta^{*}$ and $t^{*}$ affect the endogenous variables $\mathrm{X}^{*}, \mathrm{E}_{\mathrm{R}}{ }^{*}, \mathrm{w}^{*} \mathrm{r}^{*}$, and $\mathrm{P}^{*}$.

\section{ENDOGENOUS EFFECTS}

The endogenous effects of a change in natural resource scarcity values and in the rate of technological improvement are most easily investigated by considering the signs on the elasticities of (1) $P^{*}$, (2) $E_{R}^{*}-X^{*}$, (3) $w^{*}-r^{*}$, and (4) $\mathrm{N}^{*}$ with respect to these two exogenous shocks. In other words, the focus in 
this section is on relative price effects, relative output effects, relative primary factor payments, and the effects on the utilization of the natural resource commodity. As might be expected, few of these four types of elasticities are unambiguously positive or negative. However, the ambiguities themselves are of interest because, at least in part, they can be easily explained in terms of StolperSamuelson and Rybczynski effects. This subsection first considers the effects of changes in natural resource scarcity values and then turns to an examination of the role of technical improvements.

The effects of changes in natural resource scarcity values will be discussed by first jointly considering $\mathrm{P}^{*} / \delta^{*}$ and $\left(\mathrm{E}_{\mathrm{R}} / \delta^{*}\right)-\left(\mathrm{X} / \delta^{*}\right)$ and then examining $\left(\mathrm{w}^{*} / \delta^{*}\right)-\left(\mathrm{r}^{*} / \delta^{*}\right)$. The expressions for price and output changes are

$$
\frac{\mathrm{P}^{*}}{\delta^{*}}=\frac{\left(\mu_{\mathrm{K}}-\mu_{\mathrm{L}}\right)|\theta|+\left(\phi_{\mathrm{E}}-\phi_{\mathrm{X}}\right)\left(\gamma_{\mathrm{K}}-\gamma_{\mathrm{L}}\right)}{-\alpha_{\mathrm{p}}|\lambda||\theta|+\gamma_{\mathrm{K}}-\gamma_{\mathrm{L}}} \underset{<0}{\gtrless} 0
$$

and, as should be expected from the demand relation in (38)

$$
\begin{aligned}
\frac{E_{\mathrm{R}}^{*}}{\delta^{*}}-\frac{\mathrm{X}^{*}}{\delta^{*}} & =\frac{-\alpha_{\mathrm{p}}\left(\mu_{\mathrm{K}}-\mu_{\mathrm{L}}\right)|\theta|-\alpha_{\mathrm{p}}\left(\phi_{\mathrm{E}}-\phi_{\mathrm{X}}\right)\left(\gamma_{\mathrm{K}}-\gamma_{\mathrm{L}}\right)}{-\alpha_{\mathrm{p}}|\lambda||\theta|+\gamma_{\mathrm{K}}-\gamma_{\mathrm{L}}} \\
& =-\alpha_{\mathrm{p}} \frac{\mathrm{P}^{*}}{\delta^{*}}
\end{aligned}
$$

where

$$
|\theta|=\left|\begin{array}{cc}
\theta_{\mathrm{LX}} & \theta_{\mathrm{KX}} \\
\theta_{\mathrm{LE}} & \theta_{\mathrm{KE}}
\end{array}\right| \quad|\lambda|=\left|\begin{array}{cc}
\lambda_{\mathrm{LX}} & \lambda_{\mathrm{LE}} \\
\lambda_{\mathrm{KX}} & \lambda_{\mathrm{KE}}
\end{array}\right|
$$

In order to evaluate these elasticities, the denominators, which are the same in each case, are considered first. If quantity of $E_{R}$ demanded responds negatively to an increase in its price, the $\alpha_{\mathrm{p}}<0$. Also, $\gamma_{\mathrm{K}}$ was shown to be positive while $\gamma_{L}$ was shown to be negative provided that the production functions exhibit constant returns to scale and are quasi-concave. Moreover, under the assumptions of constant returns to scale and competitive equilibrium, $|\theta|=$ $\theta_{\mathrm{LX}} \theta_{\mathrm{KE}}-\theta_{\mathrm{LE}} \theta_{\mathrm{KX}}$ and is interpreted, in the context of the present model, as an indicator of direct and indirect factor intensities. That is, if $|\theta|>0(|\theta|<$ 0 ), then the generation of electricity would be relatively more capital (labor) intensive than the production of X. As Jones $(1965,559)$ and Batra (1973) have demonstrated, $|\lambda|=\lambda_{\mathrm{LX}}-\lambda_{\mathrm{KX}}=\lambda_{\mathrm{KE}}-\lambda_{\mathrm{LE}}$ is a similar indicator of direct and indirect factor intensities that must have the same sign as $|\theta|$. Therefore, $|\lambda||\theta|>0$, implying that the entire denominator will be positive and the sign of $\mathrm{P}^{*} / \delta^{*}$ will be determined entirely by the numerator.

At this point, attention is directed to the term $\phi_{\mathrm{E}}-\phi_{\mathrm{X}}$ in the numerator of $\mathrm{P}^{*} / \delta^{*}$. From Equations (34) and (35) $\phi_{\mathrm{X}}=\phi\left(\rho_{\mathrm{EX}} \rho_{\mathrm{NE}}+\rho_{\mathrm{NX}}\right)$ while $\phi_{\mathrm{E}}=$ 
$\phi \rho_{\mathrm{NE}}$ where these two parameters are interpreted as the percentage increase in costs in production of commodity $\mathrm{j}(\mathrm{j}=\mathrm{X}, \mathrm{E})$ that result from a one percent increase in $\delta=\mathrm{S}_{\mathrm{N}} / \mathrm{P}_{\mathrm{N}}$. Intuitively, $\phi_{\mathrm{E}}>\phi_{\mathrm{X}}$ if $\mathrm{N}$ is a relatively more important input in the production of $E$ than in the production of $X$. This is precisely what the difference

$$
\rho_{\mathrm{NE}}-\rho_{\mathrm{EX}} \rho_{\mathrm{NE}}-\rho_{\mathrm{NX}}=\rho_{\mathrm{NE}}\left(1-\rho_{\mathrm{EX}}\right)-\rho_{\mathrm{NX}}
$$

is measuring. In any case, if $\phi_{\mathrm{E}}>\phi_{\mathrm{X}}$ then the cost increase occasioned by the exogenous increase in $\mathrm{S}_{\mathrm{N}}$ would be relatively greater in the generation of electricity than in the production of $\mathrm{X}$. Under the assumptions of competitive equilibrium, implying that price equals marginal cost, and constant returns to scale, implying that marginal cost equals average cost, the greater relative increase in $\phi_{E}$ than $\phi_{X}$ must operate to drive up $\mathrm{P}_{E}$ by more than $\mathrm{P}_{\mathrm{X}}$. As shown by the second term in the numerator of (45), this would tend to stimulate production of $X$ and reduce the output of $E_{R}$.

The first term in the numerators of Equations (45) and (46) illustrates the role of the Rybczynski effect. As is well known, the Rybczynski theorem states that, in an economy producing only two final goods using only two primary factors, an exogenous increase (decrease) in the exogenous labor endowment or decrease (increase) in the exogenous capital endowment will cause an increase (decrease) in the output of the good using relatively more labor (capital) intensive production methods and a decrease in the output of the other. This type of effect is captured in the present model by the term $\left[\left(\mu_{\mathrm{K}}-\mu_{\mathrm{L}}\right)\right.$ $|\theta|] /\left[\alpha_{\mathrm{p}}|\lambda||\theta|+\gamma_{\mathrm{K}}-\gamma_{\mathrm{L}}\right]$. In particular, this term indicates that an exogenous increase in the price $\mathrm{P}_{\mathrm{N}}$ (through an increase in $\mathrm{S}_{\mathrm{N}}$ ) will have an effect identical to changing the endowments of capital and labor. In the discussion of Equation (43), $\mu_{L}\left(\mu_{K}\right)$ was interpreted as the aggregate percentage direct and indirect savings on labor (capital) that would result at constant output levels, wages, and rewards to capital owners from a one percent increase in $\delta$. Furthermore, recall that if $\mu_{\mathrm{L}}<0$, then $\left(\mu_{\mathrm{L}}-\mu_{\mathrm{K}}\right)<0$. Therefore, if $\mu_{\mathrm{L}}<0$, then at the initial output levels of $\mathrm{X}, \mathrm{E}_{\mathrm{R}}$, and $\mathrm{N}$, an increase in $\mathrm{S}_{\mathrm{N}}$ will result in a release of labor and an attempt to absorb more capital. The effect of this on outputs operates exactly as would simultaneous exogenous increase in L and reduction in $K$. In particular, output of $X$ would increase relative to the output of $E_{R}$ provided that $X$ is the labor intensive commodity; that is, if $|\theta|>0$. Finally, if output of $X$ rises and the output of $E_{R}$ falls, the price ratio $P_{E} / P_{X}$ should rise on the assumption that the demand schedule for each good is negatively sloped. To recapitulate, $\mathrm{P}^{*} / \delta^{*}>0$ if: (1) $\mu_{\mathrm{L}}>0$, (2) $|\theta|>0$, and (3) $\phi_{E}-\phi_{X}>0$. Conversely, if: (1) $\mu_{L}>0$, (2) $|\theta|>0$, and (3) $\phi_{E}-\phi_{X}<0$; then $\mathrm{P}^{*} / \delta^{*}<0$ while if $\mu_{\mathrm{L}}=\mu_{\mathrm{K}}=\phi_{\mathrm{E}}-\phi_{\mathrm{X}}=0$ then $\mathrm{P}^{*} / \delta^{*}=0$. This last case would arise if the economy used a Leontief type production technology $\left(\sigma_{\mathrm{ij}}^{\mathrm{k}}=\right.$ 0 for all $\mathrm{i}, \mathrm{j}$, and $\mathrm{k}$ ) and the increase in $\mathrm{S}_{\mathrm{N}}$ resulted in equal percentage cost increases to both producers of $\mathrm{X}$ and $\mathrm{E}$. The effects on the relative composition of final outputs are, then, just the opposite of the relative price effects. 
Turning next to a consideration of relative factor rewards, the relevant elasticities are

$$
\frac{\mathrm{w}^{*}}{\delta^{*}}-\frac{\mathrm{r}^{*}}{\delta^{*}}=\frac{\alpha_{\mathrm{p}}|\lambda|\left(\phi_{\mathrm{X}}-\phi_{\mathrm{E}}\right)+\left(\mu_{\mathrm{L}}-\mu_{\mathrm{K}}\right)}{-\alpha_{\mathrm{p}}|\lambda||\theta|+\gamma_{\mathrm{K}}-\gamma_{\mathrm{L}}} \underset{<}{\gtrless} 0
$$

As previously explained, the denominator of this expression is positive so that its sign is determined exclusively by the two terms in the numerator. The second of these terms shows that if $\mu_{\mathrm{L}}-\mu_{\mathrm{K}}>0$, then the difference between $\mathrm{w}$ and $r$ would be driven up. In this case, the economy would be attempting to use more labor and less capital at its initial levels of production for X, E, and $\mathrm{N}$. The first term in the numerator of (49), then, can be interpreted in terms of the Stolper-Samuelson theorem. That is, if $\phi_{E}>\phi_{X}$ then, in percentage terms, the increase in $S_{N}$ has a greater effect on production costs in electricity generation than it has on the production of $X$. This would tend to confer a relative benefit (harm) to labor and a relative harm (benefit) to capital owners if $\mathrm{X}$ is labor (capital) intensive relative to $\mathrm{E}$; that is, if $|\lambda|>0(|\lambda|<0)$. Therefore, if: (1) $\phi_{\mathrm{E}}>\phi_{\mathrm{X}}$ and $|\lambda|>0$, together with (2) $\mu_{\mathrm{L}}-\mu_{\mathrm{K}}>0$ ), then the relative benefit would accrue to the owners of capital.

The expressions in (46) and (49) also prove to be useful in determining the effect on natural resource utilization of a change in $\delta^{*}$. Totally differentiating the full employment equation for $\mathrm{N}$ (Equation (6a) ) and writing the result in relative rates of change yields

$$
\mathrm{N}^{*}=\lambda_{\mathrm{NX}} \mathrm{X}^{*}+\lambda_{\mathrm{NE}} \mathrm{E}_{\mathrm{R}}^{*}+\lambda_{\mathrm{NX}} \mathrm{R}_{\mathrm{NX}}^{*}+\lambda_{\mathrm{NE}} \mathrm{C}_{\mathrm{NE}}^{*}
$$

where $\lambda_{\mathrm{NX}}\left(=1-\lambda_{\mathrm{NE}}\right)$ denotes the fraction of $\mathrm{N}$ used both directly and indirectly in the production of $\mathrm{X}$ and

$$
\begin{aligned}
& \mathrm{R}_{\mathrm{NX}}^{*}=\left[\rho_{\mathrm{NX}} \mathrm{C}_{\mathrm{NX}}^{*}+(1-\delta) \rho_{\mathrm{EX}} \rho_{\mathrm{NE}}\left(\mathrm{C}_{\mathrm{NE}}^{*}+\mathrm{C}_{\mathrm{EX}}^{*}\right)\right] /\left[\rho_{\mathrm{NX}}+\right. \\
& \left.(1-\delta) \rho_{\mathrm{EX}} \rho_{\mathrm{NE}}\right]
\end{aligned}
$$

Finally, substituting equivalent expressions in terms of $\mathrm{w}^{*}, \mathrm{r}^{*}$, and $\delta^{*}$ for $\mathrm{R}_{\mathrm{NX}}^{*}$ and $\mathrm{C}_{\mathrm{NE}}^{*}$ and then dividing through by $\delta^{*}$ produces

$$
\frac{\mathrm{N}^{*}}{\delta^{*}}=\mu_{\mathrm{N}}+\lambda_{\mathrm{NE}}\left(\frac{\mathrm{E}_{\mathrm{R}}^{*}}{\delta^{*}}-\frac{\mathrm{X}^{*}}{\delta^{*}}\right)+\gamma_{\mathrm{N}}\left(\frac{\mathrm{w}^{*}}{\delta^{*}}-\frac{\mathrm{r}^{*}}{\delta^{*}}\right)+\frac{\mathrm{X}^{*}}{\delta^{*}}
$$

where the algebraic values of $\gamma_{N}$ and $\mu_{N X}$ are given in Appendix A. Equation (52) shows that $\mathrm{N}^{*} / \delta^{*}$ is basically a weighted average of the results on relative final output changes and relative factor reward changes that have been previously discussed. In addition, the coefficients $\mu_{N}$ and $\gamma_{N}$ have interpretations that are quite similar to those for the $\mu_{i}$ and $\gamma_{i}$ reported in (43) and (44). More specifically, $\gamma_{\mathrm{N}}$ is interpreted as the aggregate percentage direct and in- 
direct change in the use of $\mathrm{N}$ that would occur at unchanged final outputs and resource scarcity values if the wage rate (return to capital owners) increased (decreased) by one percent. Unlike $\gamma_{L}$ and $\gamma_{K}, \gamma_{N}$ is ambiguously signed. However, $\gamma_{\mathrm{N}}$ would be negative if, in the production of $\mathrm{X}$ and $\mathrm{E}$, it is sufficiently easier to substitute capital as opposed to labor for the energy inputs, $\mathrm{N}$ and $\mathrm{E}_{\mathrm{X}}$. Provided that all factors are substitutes, i.e., $\sigma_{\mathrm{ij}}^{\mathrm{r}}>0$ for all $\mathrm{i}, \mathrm{j}, \mathrm{k}, \mu_{\mathrm{N}}$ is unambiguously negative. This should not be surprising since $\mu_{N}$ represents the aggregate percentage direct and indirect aggregate percentage savings on $\mathrm{N}$ that would occur at unchanged final output levels, wage rates, and rates of return to capital owners if $\delta$ increased by one percent. Hence, $\mu_{\mathrm{N}}$ may be interpreted analogously with a pure substitution effect on the use of $\mathrm{N}$ given a change in its price.

Equation (52) is important because it shows that the use of $\mathrm{N}$ may either rise or fall in the face of rising natural resource scarcity values. That is, even though $\mu_{\mathrm{N}}<0$, an increase in $\delta{ }^{*}$ may force other adjustments in the economy that could more than offset this pure partial equilibrium substitution effect. For example, if: (1) $\phi_{X}>\phi_{E}$, (2) $\mu_{K}-\mu_{L}<0$, and (3) $|\theta|>0$, then as was previously indicated, $\left(\mathrm{E}_{\mathrm{R}}^{*} / \delta^{*}\right)-\left(\mathrm{X}^{*} / \delta^{*}\right)>0$, and considering this relative final output effect alone, the use of $\mathrm{N}$ would increase. Moreover, from (49), these three conditions are sufficient to guarantee that $\left(\mathrm{w}^{*} / \delta^{*}\right)-\left(\mathrm{r}^{*} / \delta^{*}\right)<0$. Hence, if $\gamma_{\mathrm{N}}<0$, the second and third terms in (52) would be positive. Therefore, if $\lambda_{\mathrm{NE}}$ and $\gamma_{\mathrm{N}}$ are both large in absolute value, these two terms may outweigh any negative effect that may be exerted on $\mathrm{N}^{*}$ through the first and fourth terms.

The effects of a change in technological improvements are less clear cut than those of a change in natural resource scarcity values. In fact, due to the complexity of the terms; $\beta_{\mathrm{K}}, \beta_{\mathrm{L}}, \pi_{\mathrm{X}}$, and $\pi_{\mathrm{E}}$, which were derived on the assumption that technical change affects production relations in all three industries, special cases must be considered in order to derive interpretable results. One such case is considered here, where technical change affects only the sector producing electricity, E. ${ }^{8}$ In considering this case, special attention is paid to the way in which technical change may affect the utilization of the natural resource commodity $\mathrm{N}$.

The algebraic forms for the elasticities of the endogenous variables with respect to the technical change parameter are quite similar to their counterparts for changes in natural resource scarcity values. That is,

$$
\begin{aligned}
& \frac{\mathrm{P}^{*}}{\mathrm{t}^{*}}=\frac{\left(\beta_{\mathrm{K}}-\beta_{\mathrm{L}}\right)|\theta|+\left(\pi_{\mathrm{E}}-\pi_{\mathrm{X}}\right)\left(\gamma_{\mathrm{K}}-\gamma_{\mathrm{L}}\right)}{-\alpha_{\mathrm{p}}|\lambda||\theta|+\gamma_{\mathrm{K}}-\gamma_{\mathrm{L}}} \underset{<0}{\geq} 0 \\
& \frac{\partial \mathrm{E}_{\mathrm{R}}{ }^{*}}{\partial \mathrm{t}^{*}}-\frac{\partial \mathrm{x}^{*}}{\partial \mathrm{t}^{*}}=\frac{-\alpha_{\mathrm{p}}\left(\beta_{\mathrm{K}}-\beta_{\mathrm{L}}\right)|\theta|-\alpha_{\mathrm{p}}\left(\pi_{\mathrm{E}}-\pi_{\mathrm{X}}\right)\left(\gamma_{\mathrm{K}}-\gamma_{\mathrm{L}}\right)}{-\alpha_{\mathrm{p}}|\lambda||\theta|+\gamma_{\mathrm{K}}-\gamma_{\mathrm{L}}} \\
& =\frac{>}{<} 0
\end{aligned}
$$


$\frac{\mathrm{w}^{*}}{\mathrm{t}^{*}}-\frac{\mathrm{r}^{*}}{\mathrm{t}^{*}}=\frac{-\alpha_{\mathrm{p}}|\lambda|\left(\pi_{\mathrm{X}}-\pi_{\mathrm{E}}\right)+\left(\beta_{\mathrm{L}}-\beta_{\mathrm{K}}\right)}{-\alpha_{\mathrm{p}}|\lambda||\theta|+\gamma_{\mathrm{K}}-\gamma_{\mathrm{L}}} \underset{<0}{\gtrless} 0$

where the expression for the parameters $\beta_{\mathrm{L}}, \beta_{\mathrm{K}}, \pi_{\mathrm{E}}$, and $\pi_{\mathrm{X}}$ from Appendix A simplify to

$$
\begin{aligned}
\pi_{\mathrm{X}} & =\rho_{\mathrm{EX}} \mathrm{D}_{\mathrm{E}} \\
\pi_{\mathrm{E}} & =\mathrm{D}_{\mathrm{E}} \\
\beta_{\mathrm{L}} & =\frac{\lambda_{\mathrm{LX}} \rho_{\mathrm{EX}} \rho_{\mathrm{NE}} \mathrm{B}_{\mathrm{NE}}}{\rho_{\mathrm{LX}}+(1-\delta) \rho_{\mathrm{LN}}\left(\rho_{\mathrm{NX}}+\rho_{\mathrm{EX}} \rho_{\mathrm{NE}}\right)}+\lambda_{\mathrm{LE}} \mathrm{B}_{\mathrm{NE}} \\
\beta_{\mathrm{K}} & =\frac{\lambda_{\mathrm{KX}}\left[\rho_{\mathrm{EX}} \rho_{\mathrm{KE}} \mathrm{B}_{\mathrm{KE}}+(1-\delta) \rho_{\mathrm{KN}} \rho_{\mathrm{EX}} \rho_{\mathrm{NE}} \mathrm{B}_{\mathrm{NE}}\right]}{\left(\rho_{\mathrm{KX}}+\rho_{\mathrm{EX}} \rho_{\mathrm{KE}}\right)+(1-\delta) \rho_{\mathrm{KN}}\left(\rho_{\mathrm{NX}}+\rho_{\mathrm{EX}} \rho_{\mathrm{NE}}\right)} \\
& +\frac{\lambda_{\mathrm{KE}}\left[\rho_{\mathrm{KE}} \mathrm{B}_{\mathrm{KE}}+(1-\delta) \rho_{\mathrm{KN}} \rho_{\mathrm{NE}} \mathrm{B}_{\mathrm{NE}}\right]}{\mathrm{KE}}+(1-\delta) \rho_{\mathrm{KN}} \rho_{\mathrm{NE}}
\end{aligned}
$$

in the case where technical progress affects only the generation of electricity. In order to evaluate the three elasticities in Equations (53), (54) and (55), note first that since (in absolute value $\pi_{X}<\pi_{E}$ ), technical change in the generation of $E$ must necessarily reduce costs in that sector by more than in the production of $X$. Taken separately, this effect will obviously tend to drive down $\mathrm{P}_{\mathrm{E}}$ relative to $P_{X}$, stimulate production of relatively more $E_{R}$ than $X$ and increase (decrease) the wage rental ratio if $|\lambda|<0(|\lambda|>0)$ implying that $E$ uses relatively more labor (capital) intensive production methods. However, these effects may be either reinforced or offset by the Rybczynski type effects captured by the $\beta_{\mathrm{K}}$ and $\beta_{\mathrm{L}}$ terms. In other words, if outputs of all goods were held constant, technical change in the generation of electricity would cause a release of $\mathrm{K}$ and/or $\mathrm{N}$. The extent to which these two factors are released is measured by the terms $\mathrm{B}_{\mathrm{NE}}$ and $\mathrm{B}_{\mathrm{KE}}$ in Equations (58) and (59), which are interpreted as the percentage change in $\mathrm{C}_{\mathrm{NE}}$ and $\mathrm{C}_{\mathrm{KE}}$ induced by a one percent increase in the technical change parameter. Provided that $\mathrm{B}_{\mathrm{NE}}$ and $\mathrm{B}_{\mathrm{KE}}$ are both negative, then $\beta_{\mathrm{L}}$ and $\beta_{\mathrm{K}}$ will also be negative and an increase in technical progress will, at constant outputs, result in an augmentation in both the economy's primary factors, $\mathrm{K}$ and L. An examination of Equations (58) and (59) suggests, however, that in general the sign of $\beta_{K}-\beta_{L}$ is somewhat difficult to determine. Nevertheless, if technical improvements are biased toward capital saving; that is $\mathrm{B}_{\mathrm{KE}}<0$ while $\mathrm{B}_{\mathrm{NE}}=0$, then $\beta_{\mathrm{L}}=0$. In this very special case, Equations (53), (54), and (55) indicate that if the production of $E$ is relatively more capital intensive than $X(|\theta|>0)$ then: (1) $\mathrm{P}^{*} / \mathrm{t}^{*}<$ 0 , (2) $\left(\mathrm{E}_{\mathrm{R}}^{*} / \mathrm{t}^{*}\right)-\left(\mathrm{X}^{*} / \mathrm{t}^{*}\right)>0$, and $(3)\left(\mathrm{W}^{*} / \mathrm{t}^{*}\right)-\left(\mathrm{r}^{*} / \mathrm{t}^{*}\right) \leq 0$, depending upon whether $\alpha_{\mathrm{p}}|\lambda|\left(\pi_{\mathrm{X}}-\pi_{\mathrm{E}}\right)-\beta_{\mathrm{K}} \leq 0$. On the other hand, if the production of $\mathrm{E}$ 
was relatively more labor intensive than the production of $X(|\theta|<0)$, then: (1) $\left(\mathrm{w}^{*} / \mathrm{t}^{*}\right)-\left(\mathrm{r}^{*} / \mathrm{t}^{*}\right)>0$, (2) $\mathrm{P}^{*} / \mathrm{t}^{*} \leq 0$, and thus, (3) $\mathrm{E}_{\mathrm{R}}^{*} / \mathrm{t}^{*}-\mathrm{X}^{*} / \mathrm{t}^{*} \leq 0$. Finally, if technical improvements are biased toward natural resource saving, $\mathrm{B}_{\mathrm{NE}}<0$ while $\mathrm{B}_{\mathrm{KE}}=0$, then the signs on the elasticities in Equations (53), (54), and (55) are completely ambiguous since the sign of $\beta_{K}-\beta_{L}$ can be obtained only by making very specific assumptions about the relative magnitudes of the $\rho_{\mathrm{ij}}$.

\section{CONCLUSION}

The preceding analysis, while difficult and at times tedious, does reveal one genuinely counterintuitive result: an increase in the share of natural resource price going to resource owners (effectively the same as an increase in the scarcity value of energy) may result in an increase in resource use. Of course, this argument for a possibly positively sloped energy demand relationship is only likely to hold locally over some region of the demand curve. For very high or very low energy scarcity prices, good reasons for a downward sloping relationship can be constructed (budgetary limits for example). However, this pathological situation merits closer analysis since an economy which has a locally upward sloping demand for energy would obviously have great difficulty in adjusting to increasing energy scarcity. As shown in the preceding section, three pre-conditions are necessary to allow such perverse results. They can be intuitively described as follows:

First, the generation of the intermediate energy commodity (e.g., electricity) must be more capital intensive than the production of manufactured goods (actually all other "consumed" goods). Since energy conversion is, in general, highly capital intensive one cannot reject this condition (that $|\theta|>0$ ) out of hand.

Second, the cost of producing "manufactured goods" must be increased more (as a percentage) by an increase in the resource price share paid to resource owners than the resulting increase in cost of producing intermediate energy $\left(\phi_{X}>\phi_{E}\right)$. Using oil as an example, an increase in the price of oil may well increase the cost of manufactured goods (e.g., plastics which use oil as a feedstock) more than the cost of electricity, on a percentage basis, given that the cost of producing electricity is dominated by capital costs. Again, this second precondition cannot be rejected out of hand.

Third, the percent increase in capital must exceed the percent increase in labor necessary to offset an increase to resource owners. This situation is also reasonable since most conservation measures such as insulating homes and increasing the energy efficiency of industrial processes are capital intensive.

These three conditions are likely to be necessary but not sufficient for a perverse energy demand situation to occur and further suggest that a detailed empirical analysis of the parameters of a simple general equilibrium model since those designed to encourage conservation, as defined above, may well contribute to a perverse demand relationship. 
The effects of technical change if non-neutral and occurring at different rates in different sectors may also increase rather than decrease energy demand over time. This result, while intuitively obvious, also contradicts the implications of aggregate growth models with a natural resource.

In conclusion, we suggest as a useful and hitherto ignored empirical approach for studying the energy problem the use of simple general equilibrium models which would hopefully bridge the gap between misleading aggregate growth models and extremely complex industry studies. 


\section{APPENDIX A}

To obtain the desired expressions for the $\gamma_{\mathrm{ij}}, \mu_{\mathrm{ij}}$, and $\beta_{\mathrm{ij}}$ given in Equation (3a), first recall that Equation (21) defines

$$
C_{i j}^{*}=A_{i j}^{*}+B_{i j}^{*}
$$

Using Equations (13)-(16), the $\mathrm{R}_{\mathrm{ij}}^{*}$ can be expressed in terms of the $\mathrm{C}_{\mathrm{ij}}^{*}$. For example,

$$
\begin{aligned}
\mathrm{R}_{\mathrm{LX}}^{*} & =\frac{\mathrm{C}_{\mathrm{LX}} \mathrm{C}_{\mathrm{LX}}^{*}+\mathrm{C}_{\mathrm{LN}}\left(\mathrm{C}_{\mathrm{NX}}+\mathrm{C}_{\mathrm{EX}} \mathrm{C}_{\mathrm{NE}}\right) \mathrm{C}_{\mathrm{LN}}^{*}+\mathrm{C}_{\mathrm{LN}}\left(\mathrm{C}_{\mathrm{NX}} \mathrm{C}_{\mathrm{NX}}^{*}+\mathrm{C}_{\mathrm{EX}} \mathrm{C}_{\mathrm{NE}} \mathrm{C}_{\mathrm{NE}}^{*}+\mathrm{C}_{\mathrm{EX}} \mathrm{C}_{\mathrm{NE}} \mathrm{C}_{\mathrm{EX}}^{*}\right)}{\mathrm{C}_{\mathrm{LX}}+\mathrm{C}_{\mathrm{LN}}\left(\mathrm{C}_{\mathrm{NX}}+\mathrm{C}_{\mathrm{EX}} \mathrm{C}_{\mathrm{NE}}\right)} \\
& =\frac{\rho_{\mathrm{LX}} \mathrm{C}_{\mathrm{LX}}^{*}+(1-\delta) \rho_{\mathrm{LN}}\left[\left(\rho_{\mathrm{NX}}+\rho_{\mathrm{EX}} \rho_{\mathrm{NE}}\right) \mathrm{C}_{\mathrm{LN}}^{*}+\rho_{\mathrm{NX}} \mathrm{C}_{\mathrm{NX}}^{*}+\rho_{\mathrm{EX}} \rho_{\mathrm{NE}} \mathrm{C}_{\mathrm{NE}}^{*}+\rho_{\mathrm{EX}} \rho_{\mathrm{NE}} \mathrm{C}_{\mathrm{EX}}^{*}\right.}{\rho_{\mathrm{LX}}+(1-\delta) \rho_{\mathrm{LN}}\left(\rho_{\mathrm{NX}}+\rho_{\mathrm{EX}} \rho_{\mathrm{NE}}\right)}
\end{aligned}
$$

where the remaining expressions for the $\mathrm{R}_{\mathrm{ij}}^{*}$ are derived in a similar fashion. The $\mathrm{A}_{\mathrm{ij}}^{*}$ can be written in terms of $\mathrm{w}^{*}, \mathrm{r}^{*}, \mathrm{P}_{\mathrm{E}}^{*}$, and $\mathrm{P}_{\mathrm{N}}^{*}$. For example,

$$
\mathrm{A}_{\mathrm{LX}}^{*}=\rho_{\mathrm{LX}} \sigma_{\mathrm{LL}}^{\mathrm{X}} \mathrm{w}^{*}+\rho_{\mathrm{KX}} \sigma_{\mathrm{LK}}^{\mathrm{X}} \mathrm{r}^{*}+\rho_{\mathrm{EX}} \sigma_{\mathrm{L} 2}^{*} \rho_{\mathrm{E}}^{*}+\rho_{\mathrm{NX}} \sigma_{\mathrm{LN}}^{\mathrm{X}} \rho_{\mathrm{N}}^{*}
$$

where $\sigma_{\mathrm{ij}}^{\mathrm{k}}$ denotes the Allen partial elasticities of substitution between factors of production $\mathrm{i}$ and $\mathrm{j}$ in the production of $\mathrm{k}$. Using the relationship between the own and the cross partial elasticities,

$$
\begin{aligned}
& \mathrm{A}_{\mathrm{LX}}^{*}=\left(-\rho_{\mathrm{KX}} \sigma_{\mathrm{LK}}^{\mathrm{X}}-\rho_{\mathrm{EX}} \sigma_{\mathrm{L} 2}^{\mathrm{X}}-\rho_{\mathrm{NX}} \sigma_{\mathrm{LN}}^{\mathrm{X}}\right) \mathrm{w}^{*} \\
& +\rho_{\mathrm{KX}} \sigma_{\mathrm{LK}}^{\mathrm{X}} \mathrm{r}^{*}+\rho_{\mathrm{EX}} \sigma_{\mathrm{L} 2}^{\mathrm{X}} \rho_{\mathrm{E}}^{*}+\rho_{\mathrm{NX}} \sigma_{\mathrm{LN}}^{\mathrm{X}} \rho_{\mathrm{N}}^{*}
\end{aligned}
$$

After substituting the zero profit equations ( (18) and (19)) to eliminate $\rho_{\mathrm{E}}^{*}$ and $\rho_{\mathrm{N}}^{*}$, Equation (A.4) becomes

$$
\begin{aligned}
\mathrm{A}_{\mathrm{LX}}^{*} & =\left(-\rho_{\mathrm{KX}} \sigma_{\mathrm{LK}}^{*}-\rho_{\mathrm{EX}}\left(1-\rho_{\mathrm{NE}} \rho_{\mathrm{LN}}\right) \sigma_{\mathrm{L} 2}^{\mathrm{X}}-\rho_{\mathrm{NX}}\left(1-\rho_{\mathrm{LN}}\right) \sigma_{\mathrm{LN}}^{\mathrm{X}}\right)\left(\mathrm{w}^{*}-\mathrm{r}^{*}\right) \\
& +\left(\rho_{\mathrm{EX}} \rho_{\mathrm{NE}} \sigma_{\mathrm{LE}}^{\mathrm{X}}+\rho_{\mathrm{NX}} \sigma_{\mathrm{LN}}^{\mathrm{X}}\right) \delta^{*} \\
& -\left(\rho_{\mathrm{EX}} \sigma_{\mathrm{LE}}^{\mathrm{X}} \mathrm{D}_{\mathrm{E}}-\rho_{\mathrm{NE}} \rho_{\mathrm{EX}} \sigma_{\mathrm{LE}}^{\mathrm{X}} \mathrm{D}_{\mathrm{N}}-\rho_{\mathrm{NX}} \sigma_{\mathrm{LN}}^{\mathrm{X}} \mathrm{D}_{\mathrm{N}}\right) \mathrm{t}^{*}
\end{aligned}
$$

Next, since

$$
\mathrm{B}_{\mathrm{ij}}^{*}-\mathrm{dB}_{\mathrm{ij}} / \mathrm{B}_{\mathrm{ij}}=\tau_{\mathrm{ij}} \mathrm{t}_{\mathrm{ij}}^{*} ; \tau_{\mathrm{ij}}=\frac{\partial \mathrm{B}_{\mathrm{ij}}}{\partial \mathrm{t}_{\mathrm{ij}}} \frac{\mathrm{t}_{\mathrm{ij}}}{\mathrm{B}_{\mathrm{ij}}}
$$

the appropriate expression for $\mathrm{A}_{\mathrm{ij}}^{*}$ and $\mathrm{B}_{\mathrm{ij}}^{*}$ can be substituted into (A.2) in order to arrive at the form for the $\mathrm{R}_{\mathrm{ij}}^{*}$ shown in Equation (39). Specifically: 
78

The Review of Regional Studies

$$
\begin{aligned}
\gamma_{\mathrm{LX}}=\{ & -\rho_{\mathrm{LX}} \rho_{\mathrm{KX}} \sigma_{\mathrm{LK}}^{\mathrm{X}}-(1-\delta) \rho_{\mathrm{LN}}\left(\rho_{\mathrm{NX}}+\rho_{\mathrm{EX}} \rho_{\mathrm{NE}}\right) \rho_{\mathrm{KN}} \sigma_{\mathrm{KL}}^{\mathrm{N}}-(1-\delta) \\
& \rho_{\mathrm{LN}}^{2} \rho_{\mathrm{EX}} \rho_{\mathrm{NE}} \rho_{\mathrm{KE}} \sigma_{\mathrm{KN}}^{\mathrm{E}}-\rho_{\mathrm{LX}} \rho_{\mathrm{EX}}\left(1-\rho_{\mathrm{NE}} \rho_{\mathrm{LN}}\right)\left[1-(-\delta) \rho_{\mathrm{N} ?} \rho_{\mathrm{LX}}\right] \sigma_{\mathrm{LE}}^{\mathrm{X}} \\
& -\rho_{\mathrm{LX}} \rho_{\mathrm{NX}} \rho_{\mathrm{KN}}\left[1-(1-\delta) \rho_{\mathrm{LN}}\right] \sigma_{\mathrm{LN}}^{\mathrm{X}}-(1-\delta) \rho_{\mathrm{LN}} \rho_{\mathrm{NX}} \rho_{\mathrm{LN}} \rho_{\mathrm{KX}} \sigma_{\mathrm{KN}}^{\mathrm{X}} \\
& -(1-\delta) \rho_{\mathrm{LN}}^{2} \rho_{\mathrm{NX}} \rho_{\mathrm{EX}} \rho_{\mathrm{KE}}\left(1-\rho_{\mathrm{NE}}\right) \sigma_{\mathrm{NE}}^{\mathrm{X}}-(1-\delta) \rho_{\mathrm{LN}}^{2} \rho_{\mathrm{EX}} \rho_{\mathrm{NE}}^{2} \rho_{\mathrm{KX}} \\
& \left.\sigma_{\mathrm{KE}}^{\mathrm{X}}\right\} /\left\{\rho_{\mathrm{LX}}+(1-\delta) \rho_{\mathrm{LN}}\left(\rho_{\mathrm{NX}}+\rho_{\mathrm{EX}} \rho_{\mathrm{NE}}\right)\right\}
\end{aligned}
$$

$$
\gamma_{\mathrm{LE}}=-\rho_{\mathrm{K} 2} \rho_{\mathrm{LN}} \sigma_{\mathrm{KN}}^{\mathrm{E}}-\rho_{\mathrm{KN}} \sigma_{\mathrm{KL}}^{\mathrm{N}}
$$

$$
\begin{aligned}
& \gamma_{\mathrm{KX}}=\left\{\rho_{\mathrm{KX}} \rho_{\mathrm{LX}} \sigma_{\mathrm{LK}}^{\mathrm{X}}+(1-\delta) \rho_{\mathrm{KN}}\left(\rho_{\mathrm{NX}}+\rho_{\mathrm{EX}} \rho_{\mathrm{NE}}\right) \rho_{\mathrm{LN}} \sigma_{\mathrm{KL}}^{\mathrm{N}}+(1-\delta) .\right. \\
& \rho_{\mathrm{KN}} \rho_{\mathrm{NX}} \rho_{\mathrm{LX}} \rho_{\mathrm{KN}} \sigma_{\mathrm{LN}}^{*}+\rho_{\mathrm{K} 1} \rho_{\mathrm{EX}} \rho_{\mathrm{NE}} \rho_{\mathrm{LN}}\left[1-\rho_{\mathrm{K} 2}-(1-\delta) \rho_{\mathrm{KN}} \rho_{\mathrm{N} 2}\right] \text {. }
\end{aligned}
$$$$
\sigma_{\mathrm{KE}}^{\mathrm{X}}+\rho_{\mathrm{NX}} \rho_{\mathrm{LN}}\left[1-(1-\delta) \rho_{\mathrm{KN}} \rho_{\mathrm{KX}}\right] \sigma_{\mathrm{KN}}^{\mathrm{X}}+\rho_{\mathrm{EX}} \rho_{\mathrm{KE}} \rho_{\mathrm{NE}} \rho_{\mathrm{LN}}
$$$$
[1-(1-\delta) \rho \mathrm{KN}] \sigma_{\mathrm{KN}}^{\mathrm{E}}+\rho_{\mathrm{EX}} \rho_{\mathrm{LX}}\left(1-\rho_{\mathrm{NE}} \rho_{\mathrm{LN}}\right)\left[\rho_{\mathrm{KE}}+(1-\delta) \rho_{\mathrm{KN}} \rho_{\mathrm{NE}}\right]
$$$$
\left.\sigma_{\mathrm{LE}}^{\mathrm{X}}+\rho_{\mathrm{EX}} \rho_{\mathrm{KE}} \rho_{\mathrm{NX}} \rho_{\mathrm{LN}} \rho_{\mathrm{K} 2} \delta \sigma_{\mathrm{NE}}^{\mathrm{X}}\right\} /\left\{\rho_{\mathrm{KX}}+\rho_{\mathrm{EX}} \rho_{\mathrm{KE}}\right.
$$$$
\left.+(1-\delta)\left[\rho_{\mathrm{KN}}\left(\rho_{\mathrm{NX}}+\rho_{\mathrm{EX}} \rho_{\mathrm{NE}}\right)\right]\right\}
$$

$$
\begin{aligned}
\gamma_{\mathrm{KE}}= & \left\{\rho_{\mathrm{KE}} \rho_{\mathrm{NE}} \rho_{\mathrm{LN}}\left[1-(1-\delta) \rho_{\mathrm{KN}}\right] \sigma_{\mathrm{KN}}^{\mathrm{E}}+(1-\delta) \rho_{\mathrm{KN}} \rho_{\mathrm{NE}} \rho_{\mathrm{LN}} \rho_{\mathrm{KL}}^{\mathrm{N}}\right\} / \\
& \left.\left.\left\{\rho_{\mathrm{KE}}+(1-\delta) \rho_{\mathrm{KN}} \rho_{\mathrm{NE}}\right)\right]\right\}
\end{aligned}
$$

$$
\begin{aligned}
\mu_{\mathrm{LX}}=\{\phi & (1-\delta)\left[\rho_{\mathrm{LN}} \rho_{\mathrm{EX}} \rho_{\mathrm{NE}} \rho_{\mathrm{KE}} \sigma_{\mathrm{KN}}^{\mathrm{E}}+\rho_{\mathrm{LN}} \rho_{\mathrm{NX}} \rho_{\mathrm{EX}} \rho_{\mathrm{KE}}^{2} \sigma_{\mathrm{NE}}^{\mathrm{X}}+\right. \\
& \left.\rho_{\mathrm{LN}} \rho_{\mathrm{NX}} \rho_{\mathrm{KX}} \rho_{\mathrm{KN}}^{\mathrm{X}}+\rho_{\mathrm{LN}} \rho_{\mathrm{EX}} \rho_{\mathrm{NE}}^{2} \rho_{\mathrm{KX}} \sigma_{\mathrm{KE}}^{\mathrm{X}}\right]+\rho_{\mathrm{LX}} \rho_{\mathrm{EX}} \rho_{\mathrm{NE}}[1- \\
& \left.(1-\delta) \rho_{\mathrm{LN}} \rho_{\mathrm{NE}} \sigma_{\mathrm{LE}}^{\mathrm{X}}+\rho_{\mathrm{LX}} \rho_{\mathrm{NX}}\left[1-(1-\delta) \rho_{\mathrm{LN}}\right] \sigma_{\mathrm{LN}}^{\mathrm{X}}\right\} /\left\{\rho_{\mathrm{LX}}+\right. \\
& \left.(1-\delta) \rho_{\mathrm{NX}}+\rho_{\mathrm{EX}} \rho_{\mathrm{NE}}\right\}
\end{aligned}
$$

$$
\mu_{\mathrm{LE}}=-\phi \rho_{\mathrm{K} 2}{ }^{\sigma} \mathrm{KN}
$$




$$
\begin{aligned}
\mu_{\mathrm{KX}}= & \phi\left\{\rho_{\mathrm{KX}} \rho_{\mathrm{EX}} \rho_{\mathrm{NE}}\left[1-\rho_{\mathrm{KE}}-(1-\delta) \rho_{\mathrm{KN}} \rho_{\mathrm{NE}}\right] \sigma_{\mathrm{KE}}^{\mathrm{X}}+\rho_{\mathrm{KX}} \rho_{\mathrm{NX}} \cdot\right. \\
& {\left[1-(1-\delta) \rho_{\mathrm{KN}}\right] \sigma_{\mathrm{KN}}^{\mathrm{X}}+\rho_{\mathrm{EX}} \rho_{\mathrm{KE}} \rho_{\mathrm{NE}}\left[1-(1-\delta) \rho_{\mathrm{KN}}\right] \sigma_{\mathrm{KN}}^{\mathrm{E}} } \\
& +\rho_{\mathrm{EX}} \rho_{\mathrm{KE}}\left[1-(1-\delta) \rho_{\mathrm{KN}} \rho_{\mathrm{NX}} \rho_{\mathrm{KE}}\right] \sigma_{\mathrm{NE}}^{\mathrm{X}}-\left[\rho_{\mathrm{EX}} \rho_{\mathrm{KE}}+(1-\delta) .\right. \\
& \left.\left.\left.\rho_{\mathrm{KN}} \rho_{\mathrm{EX}} \rho_{\mathrm{NE}}\right] \rho_{\mathrm{NE}} \rho_{\mathrm{LX}} \sigma_{\mathrm{LE}}^{1}-\rho_{\mathrm{KN}} \rho_{\mathrm{NX}} \rho_{\mathrm{LX}}(1-\delta) \sigma_{\mathrm{LN}}^{\mathrm{X}}\right\}\right) \\
& \left\{\rho_{\mathrm{KX}}+\rho_{\mathrm{EX}} \rho_{\mathrm{KE}}+(1-\delta) \rho_{\mathrm{KN}}\left(\rho_{\mathrm{NX}}+\rho_{\mathrm{EX}} \rho_{\mathrm{NE}}\right)\right\} \\
\mu_{\mathrm{KE}}= & \phi\left\{\rho_{\mathrm{KE}} \rho_{\mathrm{NE}}\left[1-(1-\delta) \rho_{\mathrm{KN}}\right] \sigma_{\mathrm{KN}}^{\mathrm{E}}\right\} /\left\{\rho_{\mathrm{KE}}+(1-\delta) \rho_{\mathrm{KN}} \rho_{\mathrm{NE}}\right\}
\end{aligned}
$$

Exact expressions could also be presented for the $\beta_{\mathrm{ij}}$, however, this is not done since such expressions are not needed to evaluate results given in the text. Note that if all $\sigma_{\mathrm{ij}}^{\mathrm{k}}>0$, then $\gamma_{\mathrm{LX}}$ and $\gamma_{\mathrm{LE}}$ are negative while $\gamma_{\mathrm{KX}}$ and $\gamma_{\mathrm{KE}}$ are positive. Also, an examination of (A.11) - (A.14) shows that if: (1) $\mu_{\mathrm{L}}>0$ then $\left(\mu_{\mathrm{L}}-\mu_{\mathrm{K}}\right)>0$ and (2) all production functions are of the fixed proportions type $\left(\sigma_{\mathrm{ij}}^{\mathrm{k}}=0\right.$ for all $\mathrm{i}, \mathrm{j}$, and $\mathrm{k}$ ) then $\mu_{\mathrm{L}}=\mu_{\mathrm{K}}=0$.

\section{FOOTNOTES}

1. The algebraic complexity of the results, however, increases substantially with the inclusion of additional natural resource energy commodities.

2. One might question the assumption of constant returns to scale in (3). However, production of a depletable natural resource can be viewed simply as a movement of flow from one point to another of material. Thus, the stock of coal can be depleted twice as fast if we use twice as much capital and labor.

3. Note that the zero profit equations implicitly assume that electricity producers do not discriminate between residential and commercial sales as the same price $P_{E}$ is charged to each.

4. One reason for substituting $\mathrm{N}$ out of the model is to permit more explicit attention to be devoted to the output and price of electricity in addition to $\mathrm{X}, \mathrm{w}$, and $\mathrm{r}$ variables. $\mathrm{Ob}$ - viously, the effect of changes in $\mathrm{S}_{\mathrm{N}}$ or $\mathrm{N}$ could be obtained in terms of solutions for the remaining endogenous variables. A similar argument can be made for eliminating $P_{N}$ from the zero profit equations.

5. Since, by Walras Law, only relative prices can be determined for this barter economy, $P_{X}$ is normalized to equal unity.

6. Jones (1965) has considered a similar concept in a setting where no intermediate goods are present.

7. The exact expression for $\mu_{\mathrm{L}}$ and $\mu_{\mathrm{K}}$ appear in A.12 to A.14 of Appendix A. Also, only the ambiguity in the sign of $\mu_{\mathrm{L}}$ is discussed, since the case of $\mu_{K}$ is analogous.

8. The effects of technical change on other industries could also be considered. However, the basic structure of these results are, in qualitative terms, much the same as those to be presented for the case of electricity.

\section{REFERENCES}

Batra, R. N., Studies in the Pure Theory of International Trade, St. Martin's Press, New York, 1973.

Cummings, R.G., and Schulze, W., "Ramsey, Resources, and the Conservation of Mass
Energy," Journal of Environmental Economics and Management, Forthcoming, 1980.

Georgescu-Roegen, N., "Energy and Economic Myths," Southern Economic Journal, 41 (January, 1975). 
Hotelling, H., "The Economics of Exhaustible Resources," Journal of Political Economy, 39 (April, 1931).

Jones, R.W., "The Structure of Simple General Equilibrium Models," Journal of Political Economy, 73 (Dec. 1965).

Smith, V. K., "Measuring Natural Resource Scarcity: Theory and Practice," Journal of Environmental Economics and Management, 5 (June, 1978).
Solow, R. M., "The Economics of Resources or the Resources of Economics," American Economic Review, 64 (May, 1974).

Stiglitz, J., "Growth with Exhaustible Natural Resources: Efficient and Optimal Growth Paths," Review of Economic Studies, Symposium, 1974.

Stiglitz, J., "Monopoly and the Rate of Extraction of Exhaustible Resources," Amercian Economic Review, 66 (Sept., 1976). 